\title{
Design of Music Player Software Based on Android
}

\author{
Xudong Wu \\ College of Art and Communication, Bohai University, Jinzhou, 121013, China \\ wuxudong96@sina.com
}

Keywords: mobile equipment; Android; music player; platform architecture; structural design

\begin{abstract}
With the development of communications equipment network and computer science, new generation of mobile end-user has higher requirements for the functionality and performance of mobile devices. Because Android intelligent platform occupies the first place in market share with its inherent advantages, the design of music player based on Android platform has a great significance. Firstly, This paper studies the Android platform architecture theory, fully understands the theoretical basis of the Android platform, the platform's technical framework and advantages; secondly, describes the system structural design of the music player; finally, based on the structural design describes the detailed design for music player, including design principles and implemented functions. The design of music player based on Android platform makes the mobile devices more lively and flexible, and makes people's lives more diverse.
\end{abstract}

\section{Introduction}

With the rapid growing of mobile device features and technological development, the demand for mobile devices become more sophisticated, the phone is not just a communication tool, but rather a multimedia platform, music player has become one of the important software for intelligent phone [1]. Android platform is a high level of mobile phone operating system emerged in recent years, its market share continues to rise, and more and more mobile phone manufacturers are using the operating system, mainly because of its open source and powerful functionality. Under the background of the continuous upgrading of mobile devices, the performance, good looks and powerful music library stored of the music player on mobile device strongly attract people to purchase and the pursuit for mobile devices, so on the Android platform developed a music player meet the needs of customers has good market prospects and significance.

Music Player is multimedia player software that can play a variety of music files. Since the player includes a variety of audio decoder, so it is covered by a variety of the play tool of music formats, such as: MP3 player, WMA player, MP4 players and so on. They not only have beautiful interface, but also easy to operate; and take you into a perfect music space. Music player is the visual interface of the audio decoder; its essence is a decoder contrary to various audio encoding formats. For example, ape format called Monkey's Audio decoder, flac format called flac decoder, mp3 called lame decoder [2]. The humanized interface and scalability of the music player is where the characteristics of the music player. Some music player software tend to create very beautiful interface, the operation is very simple, but lacking of scalability, support for small format; while some player supports many formats, but the interface is not pretty. Therefore, this paper summarizes the deficiencies on the music player software, designed music player based on the Android platform, as far as possible to meet people's demand for the music player software, to improve the user experience and achieve a higher value.

\section{Android Platform Architecture}

Android is a freedom and open-source operating system based on the Linux, mainly used in mobile devices such as intelligent phones and tablet PCs, is leaded and developed by Google and the Open Handset Alliance. original meaning of the Android means "robot", is the name of the open source mobile operating system based on Linux platforms, which is announced by Google on November 5, 
2007, the platform has four advantages, namely its openness, rich hardware devices, convenience of software development and excellent Google services [3]. Platform used the architecture of software stack: the underlying Linux kernel provides basic functionality; other application software is developed by the companies themselves, some programs are written in Java. Android platform are composited by the operating system (OS), middleware, user interface (UI) and application software [4].

The basic components of the Android system include Activity, Service, BroadcastReceiver and ContentProvider, etc. In addition, it also included Intent components that are responsible for passing messages between the basic components [5]. Its system architecture is same as its operating systems, uses a hierarchical architecture. Android platform is divided into four layers, from the top to the lower, level is respectively the application layer, application framework layer, the system runtime layer and the layer of the Linux kernel, Among them, the application layer includes a client, short messaging program (SMS), calendar, maps, browser, contacts management procedures; application framework using the API framework, which contains content providers, resource managers, notification manager and activity manager; system runtime library includes system C library, media library, Surface Manager and Web browser engine (LibWebCore). Android platform architecture diagram is shown in Fig. 1.

\begin{tabular}{|c|c|c|c|c|c|}
\hline \multirow{2}{*}{ Applications } & Home & Contacts & Phone & Browser & Settings \\
\hline & Calendar & Map & Calculator & Clock & $\ldots \ldots$ \\
\hline \multirow{2}{*}{$\begin{array}{l}\text { Application } \\
\text { Framework }\end{array}$} & $\begin{array}{l}\text { Activity } \\
\text { Manager }\end{array}$ & $\begin{array}{l}\text { Window } \\
\text { Manager }\end{array}$ & $\begin{array}{c}\text { Content } \\
\text { Providers }\end{array}$ & $\begin{array}{l}\text { View } \\
\text { System }\end{array}$ & $\begin{array}{c}\text { Notification } \\
\text { Manager }\end{array}$ \\
\hline & $\begin{array}{l}\text { Package } \\
\text { Manager }\end{array}$ & $\begin{array}{l}\text { Telephony } \\
\text { Manager }\end{array}$ & $\begin{array}{l}\text { Resources } \\
\text { Manager }\end{array}$ & $\begin{array}{l}\text { Location } \\
\text { Manager }\end{array}$ & $\begin{array}{l}\text { XMPP } \\
\text { Service }\end{array}$ \\
\hline \multirow{3}{*}{ Libraries } & Surface & Media Frame & SQLite & \multicolumn{2}{|c|}{ Android Runtime } \\
\hline & OpenGL/ES & FreeType & WebKit & \multicolumn{2}{|c|}{ Core Libraries } \\
\hline & SGL & $\overline{\text { SSL }}$ & libc & \multicolumn{2}{|c|}{ Dalvik Virtual Machine } \\
\hline \multirow{2}{*}{ Linux Kernel } & $\begin{array}{l}\text { Display } \\
\text { Driver }\end{array}$ & $\begin{array}{l}\text { Camera } \\
\text { Driver }\end{array}$ & $\begin{array}{l}\text { Bluetooth } \\
\text { Driver }\end{array}$ & $\begin{array}{l}\text { M-Systems } \\
\text { Driver }\end{array}$ & $\begin{array}{c}\text { Binder (IPC) } \\
\text { Driver }\end{array}$ \\
\hline & $\begin{array}{l}\text { USB } \\
\text { Driver }\end{array}$ & $\begin{array}{l}\text { Keypad } \\
\text { Driver }\end{array}$ & $\begin{array}{l}\text { Wi-Fi } \\
\text { Driver }\end{array}$ & $\begin{array}{l}\text { Audio } \\
\text { Driver }\end{array}$ & $\begin{array}{c}\text { Power } \\
\text { Management }\end{array}$ \\
\hline
\end{tabular}

Fig. 1. Android platform architecture diagram

\section{Structural Design}

Software structural design is a basic blueprint for the software implementation; software structural diagram divides the software system into several main work modules, and provides the main function of modules and the interaction between modules [6]. The music player studied in this paper mainly contains three modules, namely, music player interface modules, music library interface modules and download management modules.

Music player interface mainly includes volume control, play settings and playlist management, volume control is the control of the volume when playing music; playback settings including background playback settings, mainly in the case of exiting music player interface, Android system 
does not close program so that it runs in the background; playlist management mainly refers to rename, move, delete, create, import and export management for the play list; the main function of music library interface is to store music resources modules, including local music and online music as well as search for music based on personal preferences; download manager is to manage online play and download, including adding download tasks, delete download task, pause downloads, online play, displaying download progress and the notification when download task is completed. The software architecture diagram is shown in Fig. 2.

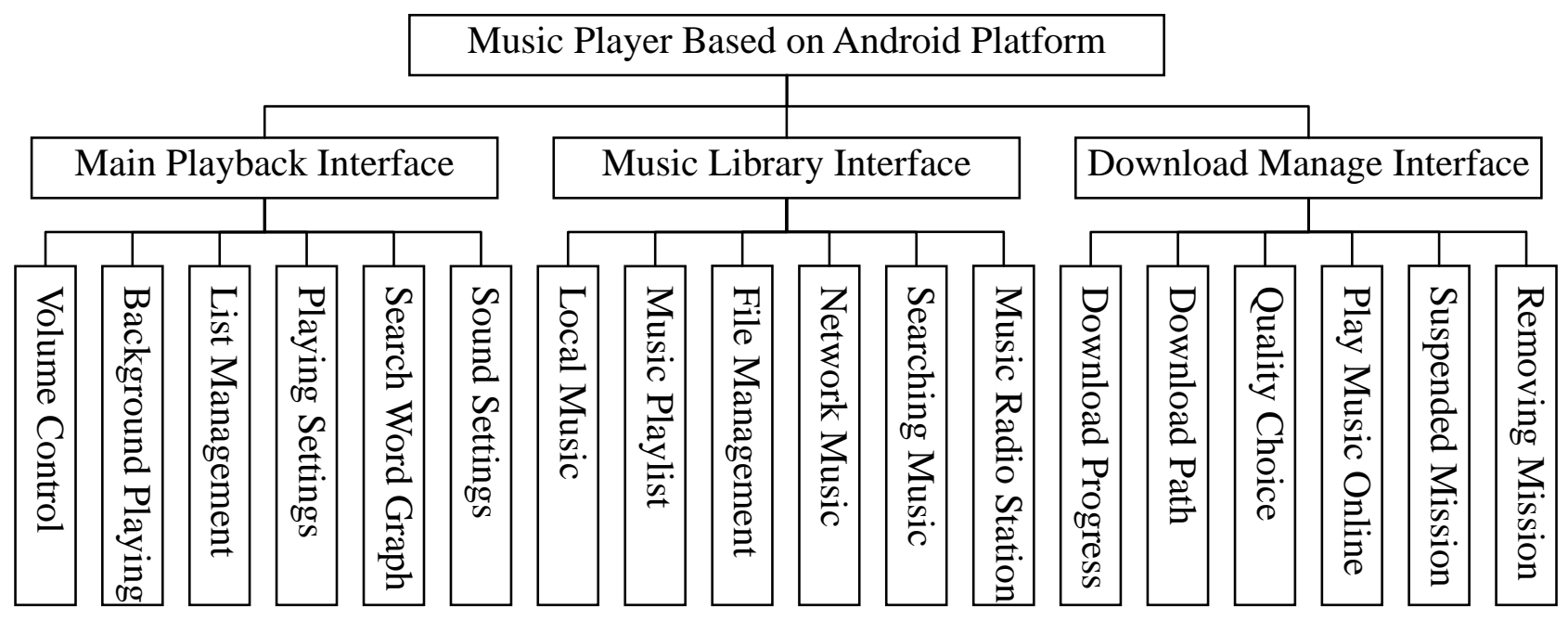

Fig. 2. System architecture diagram of music player

\section{Detailed Design}

According to the application's design features, the design principles of music player include the following aspects [7]: (1) software module level division is reasonable, fully consider loose coupling and scalability. (2) Components division is reasonable, rational division of components internal logic and packaging has a good reusability. (3) Rational design of communication. Mainly consists of inter-process communication between components, communication between the components within the process, message passing between threads. (4) Interface design is simple and aesthetics and easy to operate and reasonable switching interface. According to the principles of music player, this paper detailed design the music player on Based on Android platform, music player achieved the main player interface, music library, download manager, and other major functions.

For users, many users determine the merits of application software performance from the aspect of friendly interface and simply operating, system initialization interface is more intuitive to reflect their sense of clarity, therefore main player interface is core modules for music player, including volume control, play settings, playlist management, and other functions, volume control is mainly used to adjust the playback volume of the music, you can increase or decrease the volume. Pause for play is used to pause music playback, if the button is shown play icon, press the button, the music starts playing, icon refresh pause icon, and vice versa; the selection of next song or former song is mainly used in the playlist to switch songs; music progress bar indicates the progress of the playback song, the user can drag the progress bar to play songs at the specified position; playback settings including the order play, random play, list circulation, single player and single cycle; playlists management mainly manage playlist, includes delete, rename, move lists and other functions.

The music library interface is mainly stored songs resources, including local music and online music two aspects, local music includes artists, songs, albums, and folders; online music is the combination of the music player and mobile Internet, users can search their favourite music according to their preferences, the interface includes radio, charts, search, and my music. 
Download manager refer to when users download the songs directly added to the corresponding list, such as the music is downloaded to a personal list; including download progress bar, download path, the notification when download is completed, download sound type.

\section{Conclusion}

The large-scale commercial of domestic 3G technology promotes the rapid development of mobile Internet; intelligent platform is increasing steadily in the market. Today, the pace of life is becoming faster and faster in the society, with more and more advanced hardware mobile devices, people's demand become higher and higher for mobile devices, from the previous pursuit of technology to the current visual pursuit. Based on the key technology of the application development on the Android platform, this paper studies the design of music player. Through in-depth study the Android platform architecture and multimedia player and knowledge about threads, studied music search technology, audio capture, noise reduction, audio classification, designed intelligent music player with innovative features [8]. The mobile phone music player based on the Android operating system has four features, that is reliable, effective and scalable operation, as well as easy to maintain. Music player is designed in this article achieves basically beautiful interface, easy operating, reasonable music library design, and download management and other functions, to make up for the lack that interface and function is contradiction existed in the music player, meet the people's demand for the development of music player on mobile devices, in line with the people's desire to buy the public, based on ensuring its function, to save the cost of resources as far as possible, to ensure the convenience and reliability of the using for users, for the development of mobile devices has a promoting role. Therefore, in the mobile terminals develop applications with powerful functions, and this application is easy to operate, as well as the interface of the application is beautiful, has broad prospects for development $[9,10]$.

\section{References}

[1] Y. Ge, J. Z. Gao, "Design and Implementation of Android-based Music Player," Microcomputer \& Its Applications, vol. 33, no. 1, pp. 5-7, 2014.

[2] Baidu Baike, "namespace," http://baike.baidu.com/view/1787895.htm?fr=aladdin, 2014-9-20.

[3] Baidu Baike, "namespace," http://baike.baidu.com/subview/1241829/9322617.htm?fr=aladdin, 2014-9-20.

[4] F. Li, "Design and Implementation of MP3 Player Based on Android," Master's Degree of Beijing University of Posts and Telecommunications, 2011.

[5] J. X. Ye, W. J. Huang, "Software Solutions of Multimedia Player Based on Android Operating System," Modern Electronics Tcchnique, vol. 34, no. 24, pp. 74-76, 2011.

[6] L. J. Zhao, "Design and Implement of Audio Playback System Based on Android Platform," Master's Degree of Xi'an University of Electronic Science and Technology, 2012.

[7] J. Xu, "Design and Implementation of Media Player Based on Android," Master's Degree of Beijing University of Posts and Telecommunications, 2011.

[8] W. H. Lu, "The Design and Implementation of Online Player Based on Android Platform," Computer Knowledge and Technology, vol. 7, no. 19, pp. 4591-4593, 2011.

[9] R. Nie, C. C. Huang, "Design and Realization of Music Player Based on Android System," Microcomputer Applications, vol. 29, no. 10, pp. 23-26, 2013.

[10] F. Y. Wang, "Design and Implementation of Mobilephone Audio Player based on Android Platform," Journal of Hebei Software Institute, vol. 16, no. 1, pp. 58-60, 2014. 